\title{
Broadband Compact Quasi Yagi Antenna for UHF Wireless Communication Systems with Enhanced Performance at UHF ISM Bands
}

\author{
Yigit BAKIRLI ${ }^{1}$, Ali SELEK ${ }^{2}$, Mustafa SECMEN ${ }^{3}$ \\ ${ }^{1}$ Hanwha Q CELLS, GmbH Sonnenallee, 17 - 21 06766, Bitterfeld-Wolfen, Germany \\ ${ }^{2}$ aSAY Energy Construction Ind. Com. Inc., Gaziemir, 35410, Izmir, Turkey \\ ${ }^{3}$ Department of Electrical and Electronics Engineering, Yasar University, Bornova, 35100, Izmir, Turkey \\ y.bakirli@q-cells.com, ali.selek@asay.com.tr, mustafa.secmen@yasar.edu.tr \\ Submitted February 27, 2019 / Accepted June 17, 2020
}

\begin{abstract}
In this study, a broadband planar quasi Yagi antenna operated at ultra-high frequency (UHF) band is presented. The performance of the antenna is particularly improved for two popular UHF frequencies of 433 and $868 \mathrm{MHz}$ used in several wireless communication applications such as Long Range (LoRa), Internet of Things (IoT), Machine-to-Machine (M2M), Wireless Meter bus (M-bus), and Radio Frequency Identification (RFID). The proposed antenna includes a printed feed dipole with a ground reflector and two parasitic (director) elements on a substrate to keep total dimensions of the antenna within compact size. The parasitic elements are very thick and closely spaced to feed dipole. Significant increase in the bandwidth is obtained with the improved effects due to usage of tapered feed line and tapered reflector. The antenna's 10-dB return loss bandwidth is measured more than $70 \%$ between $428 \mathrm{MHz}$ and $896 \mathrm{MHz}$. The antenna offers moderate peak gain values of $5.5 \mathrm{dBi}$ and $5 \mathrm{dBi}$; and front-toback ratio $(F / B)$ values of $12 \mathrm{~dB}$ and $14 \mathrm{~dB}$ at lower and higher parts of UHF band around 433 and $868 \mathrm{MHz}$, respectively. The peak gain and $F / B$ ratio values are found to be minimum $4 \mathrm{dBi}$ and $8.5 \mathrm{~dB}$ within the operating bandwidth, respectively.
\end{abstract}

\section{Keywords}

Broadband antenna, UHF, planar, printed antenna, quasi Yagi, wireless communication

\section{Introduction}

In wireless communication, the antennas can be classified as mobile station (MS) and fixed/base station (FS/BS) antennas according to their motional characteristics. MS antennas should be used when both transmitter (TX) and receiver (RX) antennas are not stationary. They should have almost omnidirectional pattern characteristics in order to get the fields from the other antennas at any random angle, which results in low gain and compact structure. On the other hand, when at least one of TX or RX antenna is stationary, FS antennas with higher gain values can be used to increase the range of the communication between TX and RX antennas. FS/BS antennas are generally multi-band or wideband antennas having directional pattern and relatively larger size [1], [2].

IEEE UHF band is generally defined within the frequency band between 300 and $1000 \mathrm{MHz}$. Earlier, this band was so popular especially for UHF TV applications. Currently, it contains two Industrial, Scientific and Medical (ISM) band frequencies of 433 and $868 \mathrm{MHz}$ as defined by the International Telecommunications Union (ITU) for Europe [3], [4]. Many well-known wireless applications such as LoRa, IoT, M2M, Wireless M-bus, and RFID operate at the frequencies [5-9]. Besides, IEEE UHF band contains two ITU Radar bands, which are around $433 \mathrm{MHz}$ (420-450 MHz) and $915 \mathrm{MHz}(890-942 \mathrm{MHz})$ at which long range radar applications such as early warning are performed [10], [11].

Log-periodic antennas (LPAs) are known to give flat gain characteristics over broadband. Metallic-tube type LPAs are used especially in UHF TV band; however, they have significantly large dimensions especially along longitudinal direction to provide about $10 \mathrm{~dB}$ gain within a broadband frequency range. Smaller LPAs in UHF band with moderate gain values of 4-5 $\mathrm{dBi}$ can be achieved by using printed (planar) structure [12]. Yagi-Uda antennas can be considered as an alternative to LPAs. For the comparison, when Yagi-Uda and LPA with similar antenna dimensions are in consideration, Yagi-Uda antenna has similar wideband characteristics as LPA. Its gain variation performance over the broadband is slightly lower than that of LPA since Yagi antennas provide higher gain values and better return loss performances at certain (resonant) frequency/frequencies, while the performances of other frequencies within the band are still adequate. Traditional Yagi-Uda (or Yagi) antennas are composed of linear wire dipoles. Only one of these dipoles is excited (driven), and 
the dipoles placed in main lobe direction, which are slightly smaller than the excited dipole, are called as directors. There is also one dipole placed in back lobe direction, which is slightly larger than the excited dipole and called as a reflector. This dipole is especially effective in the suppression of back lobe radiation. On the other hand, microstrip Yagi antennas are generally planar and implemented on printed (microstrip) structures in order to get compact antennas and provide easy integration with other microstrip components. The elements of these antennas are striplines instead of linear wire dipoles as in traditional Yagi antennas. In most of the microstrip Yagi antennas, microstrip ground plane is used as reflector element instead of a reflector dipole or stripline to further minimize antenna dimensions [13]. For this reason, this element is usually called as a ground reflector rather than just a reflector. It is also excited with SMA connector in addition to driven element. Due to this difference in the configuration of reflecting element with classical Yagi antenna, the antennas using ground reflector (plane) are called as "quasi"Yagi antenna. In wideband quasi-Yagi antennas, one or two director (parasitic) elements are generally used since while the usage of high number of directors increases the gain values at desired frequencies, it reduces frequency bandwidth and increases overall size of the antenna. Since the coupling mechanism between the excited and director elements are also achieved with surface waves in the substrate, the separation between these elements can be smaller to provide enough coupling. Therefore, the antenna can be also made compact in size along director elements' direction. The thickness of these director elements is usually selected almost same as driven element's thickness [13-15]. In order to minimize asymmetry in the currents on arms of driven (main) microstrip dipoles and to increase the bandwidth, microstrip-to-coplanar strip line or microstrip-to-strip line transitions are usually used as balun feed [13], [14]. However, these structures either need to be specially designed whose results are prone to manufacturing errors or make the overall dimension of the antenna increase.

In this study, although the main is to design and implement a printed (planar) quasi Yagi antenna to be used as a FS antenna in UHF band as wide as possible, it is also specially focused on two popular ISM frequencies of 433 and $868 \mathrm{MHz}$ operated in LoRa, IoT, M2M, Wireless Mbus, and RFID. In addition to these focused frequencies, it is also aimed to obtain sufficient performances over full UHF band in order to make the antenna suitable for other possible broadband UHF applications. The structure in the proposed antenna has a main microstrip dipole operating at approximately $433 \mathrm{MHz}$. As described in preceding paragraph, a ground reflector is used in the quasi-Yagi structure. However, this reflector is designed to have triangular tapered geometry in order to increase the area of the ground plane by keeping the distance between the main dipole and the reflector constant. This geometry is observed to improve $\mathrm{F} / \mathrm{B}$ performance at the frequencies around $433 \mathrm{MHz}$. Two director (parasitic) elements are used; however, as being one of main differences with other studies, these elements are selected to be quite thick and closely spaced to each other. This selection greatly improves the overall frequency bandwidth and gain values at frequencies around $868 \mathrm{MHz}$. As the feed of the main dipole, a traditional linearly tapered microstrip line-to-parallel stripline balun is used, which extends from the ground reflector to the main dipole. Therefore, the proposed antenna needs no complex balun design.

There are studies implementing planar Yagi antennas in the literature; however, broadband studies cover different frequency band higher than UHF band [14-19], while the ones operated at UHF band are mainly represented for single (narrow) band applications [20], [21]. Wideband studies at other frequency bands either have narrower bandwidth in percentage [14-16] or are larger in size [17-19] as compared to the proposed antenna in this study. The proposed antenna has a broad bandwidth of more than $70 \%(428-896 \mathrm{MHz})$, and provides the dimensions of $0.428 \lambda_{0} \times 0.325 \lambda_{0}$ where $\lambda_{0}$ is the free-space wavelength of the lowest frequency in the band. Thus, it can be introduced as the first quasi Yagi antenna covering great portion of UHF band having relatively compact structure. It has also improved performance at two popular ISM frequencies of 433 and $868 \mathrm{MHz}$ by giving higher than $5 \mathrm{dBi}$ gain and better than $12 \mathrm{~dB} F / \mathrm{B}$ ratio values.

\section{The Geometry and Design Analysis of the Proposed Quasi Yagi Antenna}

The proposed antenna shown in Fig. 1 is designed to give dual resonance frequencies at around $433 \mathrm{MHz}$ and $868 \mathrm{MHz}$, and to provide wide bandwidth within UHF band between 400 and $900 \mathrm{MHz}$ as possible. Here, in order to make the antenna as compact as possible and perform easy manufacturing, the design is implemented on A4 panel size (approximately $304.8 \mathrm{~mm} \times 228.6 \mathrm{~mm}$ or 12 inches $\times 9$ inches) of Rogers $4003 \mathrm{C}$ dielectric substrate. This low-loss substrate is selected to have the thickness of $h=1.52 \mathrm{~mm}$, relative permittivity of $\varepsilon_{\mathrm{r}}=3.55$ and loss tangent of $\tan \delta=0.0027$.

In the design, it is aimed to acquire lower resonance frequency around $433 \mathrm{MHz}$ with the main dipole, and the upper resonance frequency of UHF ISM band (around $868 \mathrm{MHz}$ ) is obtained with closely spaced thick parasitic elements, which also serve as directors for lower resonance frequency performing an increase in the gain at that frequency. The tapered reflector in the structure acts as a ground plane for the main dipole and parasitic elements to increase the gain in the main lobe direction $(+y$ direction in Fig. 1a) and suppress the propagation in the back lobe (-y direction in Fig. 1a). For this purpose, the horizontal length of the main dipole should be less than the width of the reflector dipole. As shown from Fig. 1b, one arm of the main dipole has the dimension of $L 2$, which gives the total horizontal length of the dipole as almost $(2 \times L 2)$. However, 


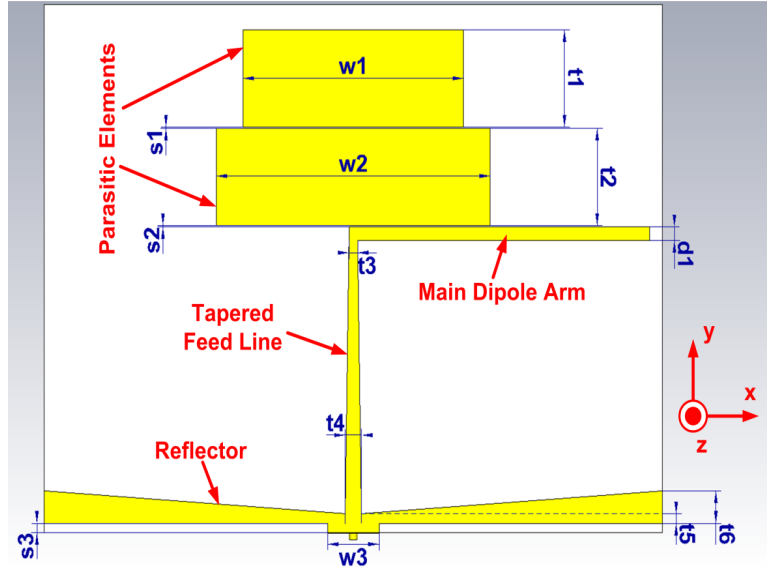

(a)

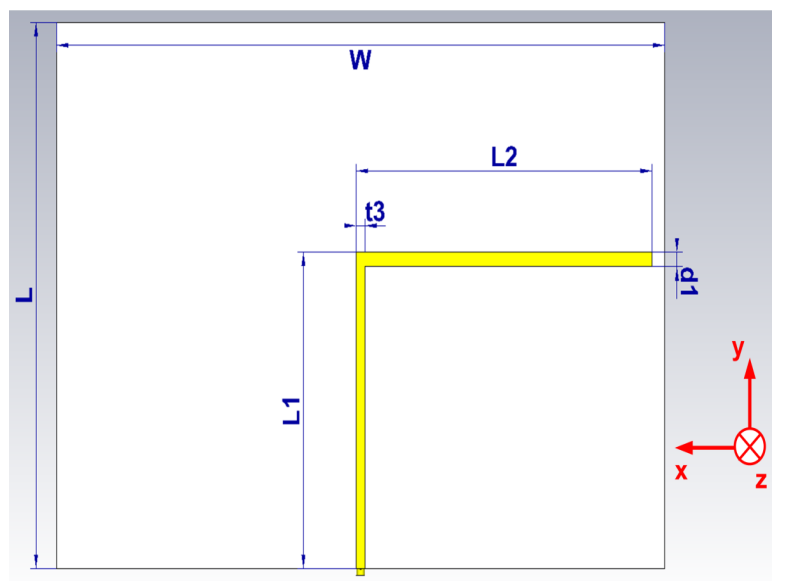

(b)

Fig. 1. The structural view for the designed planar quasi Yagi antenna in this study: (a) front view, (b) back view.

when a half wavelength dipole is considered and even the entire width of A4 panel size is used, this dimension corresponds to almost $500 \mathrm{MHz}$ in free space, which is quite far away from the desired ISM frequency of $433 \mathrm{MHz}$. However, loading effect of dielectric material makes the main dipole being keeping inside the substrate dimensions.

The values of the parameters in Fig. 1 are obtained after a thorough optimization process carried out with the electromagnetic software program of CST Microwave Studio. The final dimensions for all parameters of the antenna depicted in Fig. 1 are summarized in Tab. 1. In the design, acceptable return loss, gain and $\mathrm{F} / \mathrm{B}$ ratio performances are aimed. For the performance of return loss, $\mathrm{S}_{11}$

\begin{tabular}{|c|c|c|c|}
\hline Parameter & Dimension $[\mathrm{mm}]$ & Parameter & Dimension [mm] \\
\hline$d 1$ & 6 & $t 6$ & 14 \\
\hline$s 1$ & 0.5 & $w 1$ & 107 \\
\hline$s 2$ & 0.5 & $w 2$ & 130 \\
\hline$s 3$ & 4 & $w 3$ & 25 \\
\hline$t 1$ & 42 & $L$ & 228 \\
\hline$t 2$ & 42 & $L 1$ & 132 \\
\hline$t 3$ & 4.2 & $L 2$ & 146 \\
\hline$t 4$ & 8 & $W$ & 300 \\
\hline$t 5$ & 4 & & \\
\hline
\end{tabular}

Tab. 1. The optimized dimension values of the proposed quasi Yagi antenna.

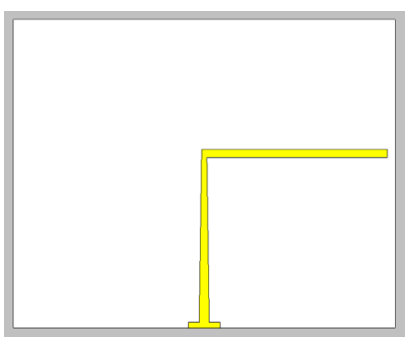

(a)

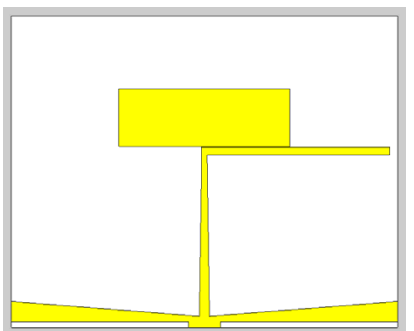

(c)

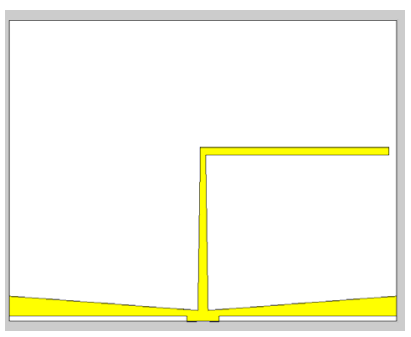

(b)

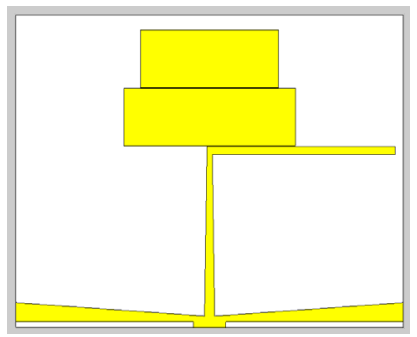

(d)
Fig. 2. The design steps (progress) of the proposed antenna: (a) Antenna 1, (b) Antenna 2, (c) Antenna 3, and (d) Antenna 4 (proposed structure). All views belong to the front side while back sides of all antennas are same with Fig. 1b.

(or reflection coefficient) values at $433 \mathrm{MHz} / 868 \mathrm{MHz}$ and within a wideband at UHF band are targeted to be $-10 \mathrm{~dB}$ at most, which corresponds to minimum $10 \mathrm{~dB}$ return loss.

The design process and procedure of the proposed antenna can be explained with a four-step progress in the antenna structure as demonstrated in Fig. 2. Here, while the front sides of the antennas are modified according to design step order, back side of all antennas are exactly same with proposed antenna in Fig. 1b.

For the configuration of antenna 1 in Fig. 2a, the antenna can be said to be fed with a classical microstrip line. The patch at the bottom of Fig. 1a with the dimensions of $w 3 \times s 3$ is the ground plane for the feeding line at back view in Fig. $1 \mathrm{~b}$ with a width of $t 3=4.2 \mathrm{~mm}$. This width is calculated to give around $Z_{0}=50 \Omega$ characteristic impedance along vertical feed line up to main dipole. The ground plane dimensions are optimized to be used as a feeding point patch, which is a known technique for bandwidth enhancement [22], [23]. While the feeding line at the back side of the antenna has constant width of $t 3=4.2 \mathrm{~mm}$ along vertical direction (along $+y$ axis in Fig. 1b), the width of the feeding line at the front side has triangular tapering that values are decreased from $t 4$ to $t 3=4.2 \mathrm{~mm}$ along longitudinal axis. It is found from the simulations that the triangular tapering, which works as a microstrip balun to feed the main dipole, is found to maintain wider bandwidth than the straight feeding lines on the both sides of the antenna (for the case where $t 3=t 4$ ) as demonstrated in simulation results in the following section. From the parametric studies carried out, it is also obtained that the increase in $t 4$ value provides wider return loss bandwidth up to a certain value of $t 4$, and the bandwidth performance decreases when this value is exceeded. Therefore, the dimension of $t 4$ should be optimized to acquire the widest 


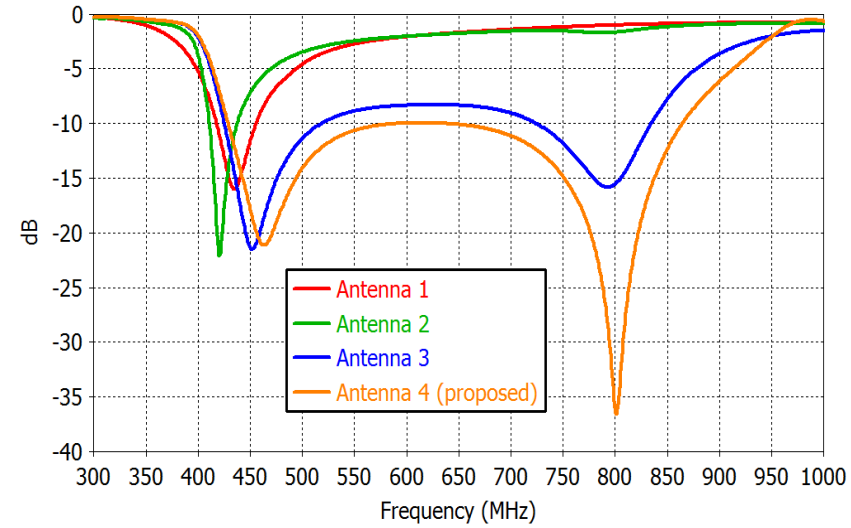

(a)

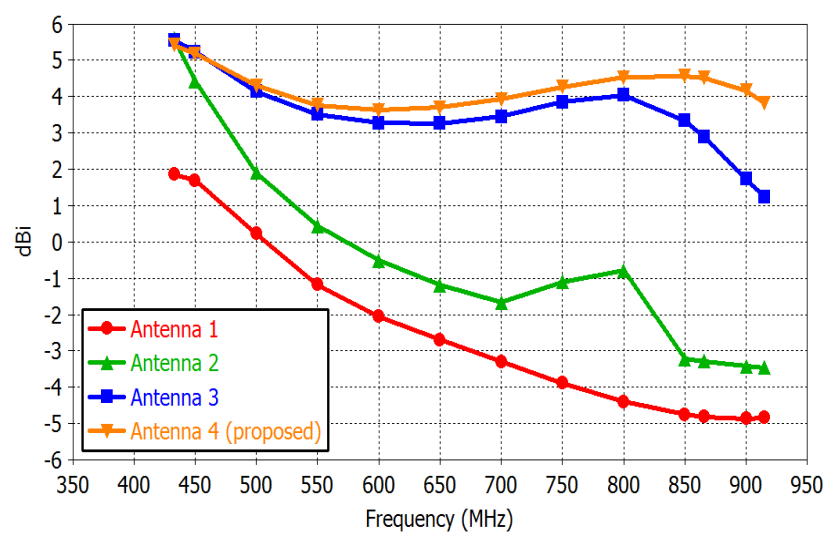

(b)

Fig. 3. (a) The simulated $S_{11}$ values and (b) realized peak gain values for the antennas in Fig. 2.

bandwidth as possible. The corresponding $S_{11}$ and peak gain values for antenna 1 are given in Fig. 3 along with the results of other antennas in Fig. 2.

Since antenna 1 is a traditional resonant microstrip dipole, there is only one resonance occurred at about $433 \mathrm{MHz}$ in Fig. 3a. The peak gain of the antenna is almost $2 \mathrm{dBi}$ at $433 \mathrm{MHz}$, which is close to standard gain value of $\lambda / 2$ dipole, which is $2.15 \mathrm{dBi}$. By considering the total length of a thin dipole as $2 \times L 2=292 \mathrm{~mm}$, which is approximately equal to $0.48 \lambda=0.48 \lambda_{0} / \sqrt{ }_{\varepsilon_{\text {reff }}}$ at $433 \mathrm{MHz}$ [24], dielectric loading effect of the substrate provides an effective relative permittivity of $\varepsilon_{\mathrm{r}, \mathrm{eff}} \cong 1.3$, which reduces length of dipole by a factor of about 1.14 as compared to free-space length.

In the next step of the design process, a ground reflector is added as shown in Fig. $2 b$ in order to increase the peak gain and $\mathrm{F} / \mathrm{B}$ ratio at $433 \mathrm{MHz}$ where the latter is almost $0 \mathrm{~dB}$ for antenna 1 . The distance between the reflector and the main dipole, which can be calculated as $L 1-(d 1+s 3+t 5)$ in Fig. 1 , is generally given as quarter wavelength in optimal [12]. The selection of the value of this parameter is very critical in the design. If this distance is selected too short as being close to quarter wavelength $(\lambda / 4)$ at $868 \mathrm{MHz}$; although gain in the front direction and suppression in the back direction (or equivalently front-toback F/B ratio) are improved at $868 \mathrm{MHz}$, the suppression and F/B ratio values are severely degraded at $433 \mathrm{MHz}$.
This is due to the reason that since the reflector acting as a ground plane is electrically smaller at the lower frequency as compared to upper frequencies; the ground plane effect employing suppression at back lobe is poorer at $433 \mathrm{MHz}$. The performance of $\mathrm{F} / \mathrm{B}$ ratio at $433 \mathrm{MHz}$ can be only compensated with larger distance value between reflector and driven (main) dipole as being almost $\lambda / 4$ at $433 \mathrm{MHz}$. On the other hand, if the distance is selected as approximately $\lambda / 4$ at $433 \mathrm{MHz}$, the length of overall antenna can again exceed the dimensions of A4 panel size. Besides, the distance between parasitic elements and reflector becomes almost $\lambda / 2$ at the upper desired frequency of $868 \mathrm{MHz}$. Therefore, the reflector along with parasitic elements makes low radiation especially in the main lobe direction $(+y$ direction) resulting in low gain performance at $868 \mathrm{MHz}$. Due to these reasons, the distance between the center points of the main dipole and the reflector is selected to be equal to approximately $\lambda / 4$ at the center frequency (mean of lower and upper UHF ISM frequencies) of $650 \mathrm{MHz}$.

The reflector dipole described in the previous paragraph and placed at the bottom part in Fig. 1a extends over almost entire width $(W)$ of the A4 panel size of substrate to make the ground plane for the main dipole and parasitic elements as electrically large as possible. This results in $W=300 \mathrm{~mm}$ width for the reflector, which corresponds to $\lambda / 2$ electrical length at $500 \mathrm{MHz}$. The thickness of the reflector, $t 5$, should be also large to provide sufficient ground plane characteristics as explained before. If the thickness value of $t 5$ is selected too thick by employing an extension along $+y$ direction in Fig. 1a, it is found from the parametric studies in the simulations that thicker reflector values degrade the bandwidth performance of the antenna since the distance between center points of the main dipole and the reflector is lowered. On the other hand, when the thickness is increased along $-\mathrm{y}$ direction in Fig. 1, although it performs a slight effect on bandwidth, it causes a significant extension in the total height of the antenna ( $L$ value in Fig. 1b) such that overall antenna may not fit to A4 panel size when the parasitic elements are considered. Thin $t 5$ values might be good for better return loss in wider bandwidth; however, it significantly gives low $\mathrm{F} / \mathrm{B}$ ratio values at around $433 \mathrm{MHz}$ due to problem of electrically small ground plane at these frequencies. Therefore, the thickness of the reflector has an optimized value. However, even for the optimized value of $t 5$ giving sufficiently wide return loss bandwidth, $\mathrm{F} / \mathrm{B}$ ratio values are found to be not better than $6 \mathrm{~dB}$ at around $433 \mathrm{MHz}$ when straight reflector dipole is used (for the case where $t 5=t 6$ in Fig. 1a). F/B values on the order of these levels are not desired in practical applications that minimum $\mathrm{F} / \mathrm{B}$ value of $10 \mathrm{~dB}$ is usually used. Therefore, as being one of the main novelties in the antenna design, the geometry of the reflector dipole is modified to triangular tapering (as like triangularly tapered geometry of feed line), which is shown in Fig. 1a. The idea behind this geometry is to keep the distance between the center points of main dipole and reflector constant and to increase the electrical size of the reflector with triangular 
tapering as possible. For the values of $t 5<t 6$, while the forward gain along main lobe is slightly lowered with respect to the straight-line case $(t 5=t 6)$, the back lobe is considerably suppressed. Larger values of $t 6$ make more effective suppression at the back lobe due to providing larger electrical size of reflector (ground plane). However, in the design, in order not to make gain drop in main lobe too much, the value of $t 6$ is increased until $\mathrm{F} / \mathrm{B}$ ratio of more than $10 \mathrm{~dB}$ around $433 \mathrm{MHz}$ is observed. The $\mathrm{S}_{11}$ and peak gain values for antenna 2 is given in Fig. 3 such that the peak gain is increased more than $3 \mathrm{dBi}$ at $433 \mathrm{MHz}$ as the consequence of increase in $\mathrm{F} / \mathrm{B}$ ratio at that frequency. The lower resonance frequency is preserved around $433 \mathrm{MHz}$ with a small shift towards left $(425 \mathrm{MHz})$, and a weak resonance begins to be observed about $800 \mathrm{MHz}$ at which noticeable increase in the peak gain value from antenna 1 to antenna 2 can be remarked.

In the next steps of the antenna design, two thick and closely spaced directors as given in Fig. 2a and Fig. $2 b$ are used to achieve the resonance frequency at upper UHF ISM band around $868 \mathrm{MHz}$. These parasitic elements increase gain performances especially at around desired ISM frequencies of 433 and $868 \mathrm{MHz}$ by acting as directors to former frequency and as main radiators for latter frequency. It is expected that since the main dipole excited at around $433 \mathrm{MHz}$ is directly fed by a microstrip line, and radiators at $868 \mathrm{MHz}$ are excited with coupling mechanism, the antenna provides relatively higher gain at lower ISM frequency of $433 \mathrm{MHz}$ within UHF band.

In the traditional Yagi antennas, quite thinner directors are usually used with much higher spacing values. However, as being the other novelty of the proposed antenna, it is parametrically found from the simulation results that thicker and closer director elements present better return loss performance especially at the mid-band. Therefore, the thickness of the directors ( $t 1$ and $t 2)$ are selected as thick as possible, and the spacing values between directors $(s 1)$ and the distance between the adjacent director and the main dipole $(s 2)$ are selected as small as possible. Besides, the width values of the directors, $w 1$ and $w 2$, are found to be very effective on the value of the second (upper) resonance frequency. Although the resonant length is almost $0.48 \lambda$ for thin microstrip dipole as the main dipole in the structure, the resonant length of directors drops to about $0.45 \lambda$ since these directors are thick microstrip dipoles [24]. Besides, dielectric loading effect of directors is greater than that of the main dipole due to directors' larger thickness. By considering length of the first director as $w 1=130 \mathrm{~mm}$, which is equal to $0.45 \lambda=0.45 \lambda_{0} / \widehat{V}_{\mathrm{r} \text {,eff }}$ at upper resonance of $800 \mathrm{MHz}$, dielectric loading effect for the first director gives $\varepsilon_{\mathrm{r} \text {,eff }} \cong 1.7$, which is greater than that of the main dipole as expected. The second director with $w 2=107 \mathrm{~mm}$ has almost $80 \%$ of the first director in length. Therefore, the first director with its resonant length at $800 \mathrm{MHz}$ actually behaves as the main radiator at around $800 \mathrm{MHz}$, and the second director behaves as the only director of this main radiator, which improves resonance of upper frequency at $800 \mathrm{MHz}$.
When $S_{11}$ and peak gain values of antenna 3 and antenna 4 (the proposed antenna) are examined at Fig. 3, the parasitic elements add a much stronger upper resonance at about $800 \mathrm{MHz}$ than antenna 2. For antenna 3 with one director, the peak gain values up to $800 \mathrm{MHz}$ are substantially improved. However, gain values after $800 \mathrm{MHz}$ are still not sufficient. Besides, antenna 3 can be concluded to have two narrow bands around $460 \mathrm{MHz}$ and $800 \mathrm{MHz}$ rather than a broadband antenna for impedance bandwidth of $\left|\mathrm{S}_{11}(\mathrm{~dB})\right|<-10 \mathrm{~dB}$. The addition of the second director in antenna 4 (the proposed antenna), makes the improvement in peak gain values at around $868 \mathrm{MHz}$, and reduces $\mathrm{S}_{11}$ values below $-10 \mathrm{~dB}$ in the mid-band.

\subsection{The Effect of Tapered Parts on the Performance of the Antenna}

In order to examine the effect of triangular tapering of the feed line especially on the performance of antenna's return loss (return loss bandwidth), the reflection coefficients of the designed antenna with the parametric values given in Tab. 1 are shown in Fig. 4 along with the antenna having straight (non-tapered) feed line.

According to the results given in Fig. 4, it can be observed that the tapered feed line provides significant improvement in return loss bandwidth as compared to straight feed line. The $S_{11}$ values exceed even $-8.5 \mathrm{~dB}$ for the straight feed line case such that when $10-\mathrm{dB}$ return loss bandwidth is considered, the antenna with straight feed line can be evaluated as dual band rather than wideband. Besides, the return loss values at the critical frequencies of $433 \mathrm{MHz}$ and $868 \mathrm{MHz}$ focused in this study are found to be lower than $10 \mathrm{~dB}$ for straight feed line where they are about $11.5 \mathrm{~dB}$ and $10 \mathrm{~dB}$ in the case of tapered feed line, respectively. The antenna with tapered feed line, which is the proposed structure, has quite wide $10-\mathrm{dB}$ return loss band between $428 \mathrm{MHz}$ and $868 \mathrm{MHz}$. As compared to lower and upper bands, mid-band (between $550 \mathrm{MHz}$ and $700 \mathrm{MHz}$ ) has relatively poorer $\mathrm{S}_{11}$ values; however, they are still sufficient as being smaller than $-10 \mathrm{~dB}$.

In order to enhance the performances at $433 \mathrm{MHz}$ and $868 \mathrm{MHz}$, the return losses at these frequencies can be improved by varying the dimensions of the main dipole and parasitic elements, which can shift down dip frequency of $460 \mathrm{MHz}$ and increase the dip frequency of $800 \mathrm{MHz}$ in Fig. 2. However, as these dip frequencies move towards $433 \mathrm{MHz}$ and $868 \mathrm{MHz}$, the reflection coefficient values in the mid-band become worse (higher than $-10 \mathrm{~dB}$ ). Similarly, the $S_{11}$ performance of mid-band can be also improved by shifting up the dip frequency of $460 \mathrm{MHz}$ and shifting down the dip (resonance) frequency of $800 \mathrm{MHz}$. However, this makes a considerable reduction in the bandwidth such that $S_{11}$ values at $433 \mathrm{MHz}$ and $868 \mathrm{MHz}$ become probably worse than $-10 \mathrm{~dB}$. The performances at $433 \mathrm{MHz}, 868 \mathrm{MHz}$ and mid-band can be simultaneously improved by adding a third closely spaced parasitic element and re-optimizing all antenna dimensions to give 


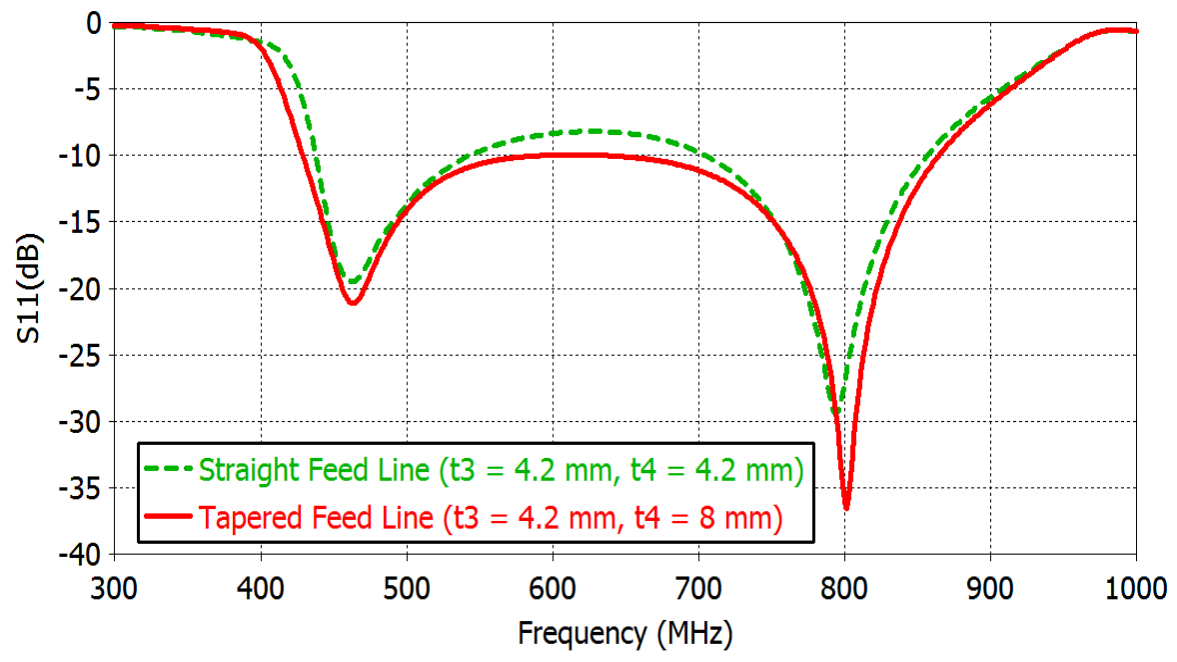

Fig. 4. The simulated $S_{11}$ values of the designed antenna with straight and tapered feed lines.

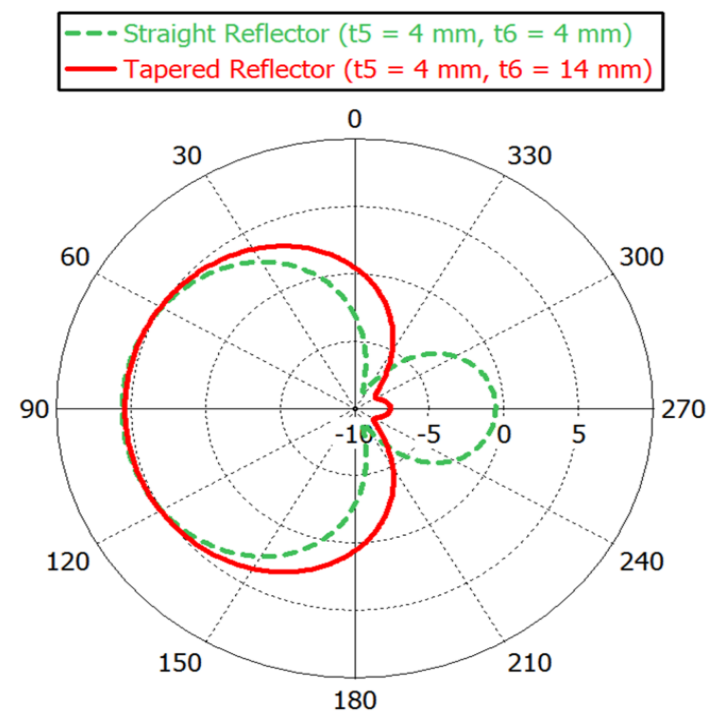

(a)

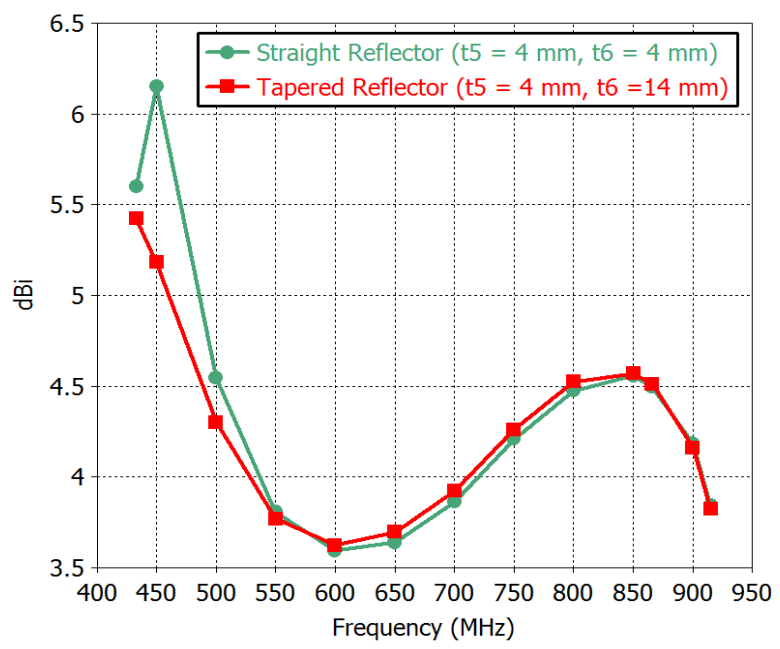

(b)

Fig. 5. (a) H-plane simulated gain radiation patterns at $433 \mathrm{MHz}$ for straight and tapered reflectors. (b) Simulated peak gain values for straight and tapered reflectors. resonances at lower, mid and upper bands such as $433 \mathrm{MHz}, 650 \mathrm{MHz}$ and $868 \mathrm{MHz}$, respectively. However, the addition of the third parasitic element makes the increase in the overall dimensions of antenna. Therefore, all dimensions of antenna in the proposed structure are optimized to give $S_{11}$ values below $-10 \mathrm{~dB}$ at $433 / 868 \mathrm{MHz}$ and at frequencies between $433 \mathrm{MHz}$ and $868 \mathrm{MHz}$ in a compact way.

In order to verify the effectiveness of the tapered reflector structure in the suppression of back lobe especially at $433 \mathrm{MHz}$, the simulated radiation patterns at $433 \mathrm{MHz}$ for both straight and tapered reflector structures are depicted in Fig. 5a. Here, the gain patterns for H-plane, which is at $\phi=90^{\circ}$ or yz plane in Fig. 1, are demonstrated. In Fig. 5a, the angle of $\theta=90^{\circ}$, which corresponds to $+y$ direction in Fig. 1, shows main lobe direction while $\theta=270^{\circ}$ (or $-\mathrm{y}$ direction in Fig. 1) is along back lobe. Figure 5a presents that while the tapered reflector has almost no effect on the main lobe (consequently forward gain) at $433 \mathrm{MHz}$, it efficiently suppresses back lobe by giving $\mathrm{F} / \mathrm{B}$ ratio values of about $13.5 \mathrm{~dB}$ and $6.2 \mathrm{~dB}$ for the tapered and straight reflector structures, respectively. The simulated gain values for straight and tapered cases are also given in Fig. 5b. It can be deduced from the gain values in Fig. 5b that tapered reflector insignificantly affects the radiation patterns (forward gain and $\mathrm{F} / \mathrm{B}$ ratio values) for the frequencies above $500 \mathrm{MHz}$. This is due to the reason that even the straight reflector structure can procure sufficient ground plane effect in electrical size for the upper frequencies. The tapered reflector introduces a gain drop especially at the lower frequencies around $433 \mathrm{MHz}$ as expected. The gain drop is about $0.2 \mathrm{~dB}$ at $433 \mathrm{MHz}$ where it can increase up to $0.8 \mathrm{~dB}$ for the frequency region between $450 \mathrm{MHz}$ and $500 \mathrm{MHz}$. However, it is again acquired from simulation results that the tapered reflector structure causes F/B ratio values being more than $10 \mathrm{~dB}$ at this frequency region where $F / B$ values are below $10 \mathrm{~dB}$ for the case with straight reflector. 


\subsection{Analysis for Radiation Mechanism}

In order to understand the radiation mechanism of the proposed antenna at lower and upper frequency bands, the surface current distributions at certain critical frequencies are obtained with simulations carried out in CST Microwave Studio. These frequencies are selected as two UHF ISM frequencies of $433 \mathrm{MHz}$ and $868 \mathrm{MHz}$, and two dip (resonance) frequencies of $460 \mathrm{MHz}$ and $800 \mathrm{MHz}$ by considering $S_{11}$ response of the antenna given in Fig. 4. The simulated surface current distributions for these frequencies are depicted in Fig. 6.

When the surface current distributions in Fig. 6a and Fig. $6 \mathrm{~b}$ are examined, it can be stated that the radiation mechanism at lower band of the antenna $(433 \mathrm{MHz}$ and $460 \mathrm{MHz}$ ) is mainly contributed from the main dipole and the ground reflector. A significant surface current on the ground reflector plays an important role in the increase of main lobe radiation and in reduction of back lobe radiation. From the surface current values at directors, parasitic elements have very low effect on the radiation mechanism of the antenna at lower part of operating frequency band.

From the surface current distributions given at Fig. 6c and Fig. 6d, it can be observed that radiation mechanism is mainly due to the coupling between the main dipole and the directors such that the ground reflector has almost no contribution. At $800 \mathrm{MHz}$, significant wave couplings exist both between the main dipole and the first director, and between the first and second directors. This fact also explains gradual increase in the peak gain values in Fig. $3 \mathrm{~b}$ from antenna 2 to antenna 4 (the proposed structure). On the other hand, coupling from the first parasitic element to the second element is stronger at $868 \mathrm{MHz}$ as compared to coupling between the main dipole and the first parasitic at

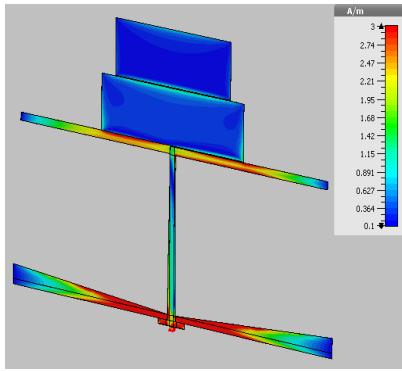

(a)

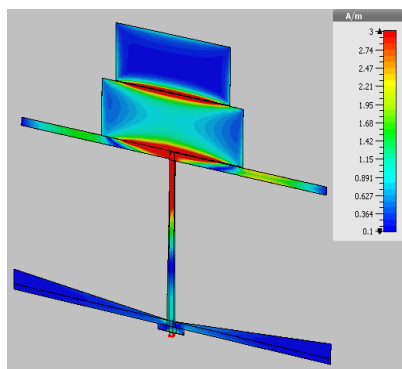

(c)

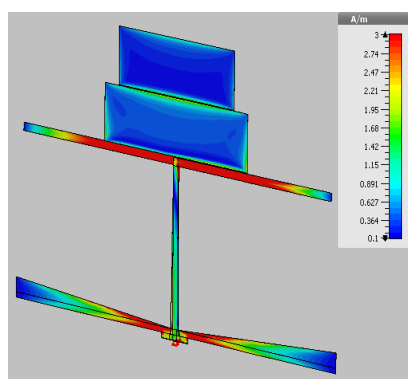

(b)

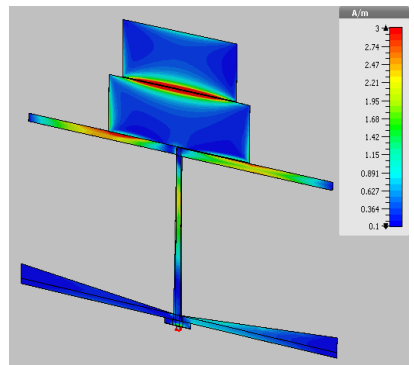

(d)
Fig. 6. The simulated surface current distributions of the proposed antenna for (a) $433 \mathrm{MHz}$, (b) $460 \mathrm{MHz}$, (c) $800 \mathrm{MHz}$, and (d) $868 \mathrm{MHz}$. the same frequency. Therefore, the addition of the second director is more crucial for the performances of peak gain and main lobe radiation at $868 \mathrm{MHz}$ rather than $800 \mathrm{MHz}$. This is also consistent with the improvement of the peak gain in Fig. 3b from antenna 3 to antenna 4 at $868 \mathrm{MHz}$, which is much greater than the gain increase for $800 \mathrm{MHz}$.

\section{Manufacturing and Measurement Results}

After the gathering of the simulation results of the proposed antenna, the antenna is manufactured as shown in Fig. 7 to verify the design. Here, while the front side in Fig. 7a includes the feeding point patch, triangular tapered reflector, triangular tapered feed line, main (driven) dipole arm and parasitic elements (directors); the back side in Fig. $7 \mathrm{~b}$ contains just the main dipole arm and the straight feeding line. The antenna has total dimensions of $300 \mathrm{~mm}$ by $228 \mathrm{~mm}$.

After the manufacturing of the proposed antenna, the performances of the antenna are measured and compared

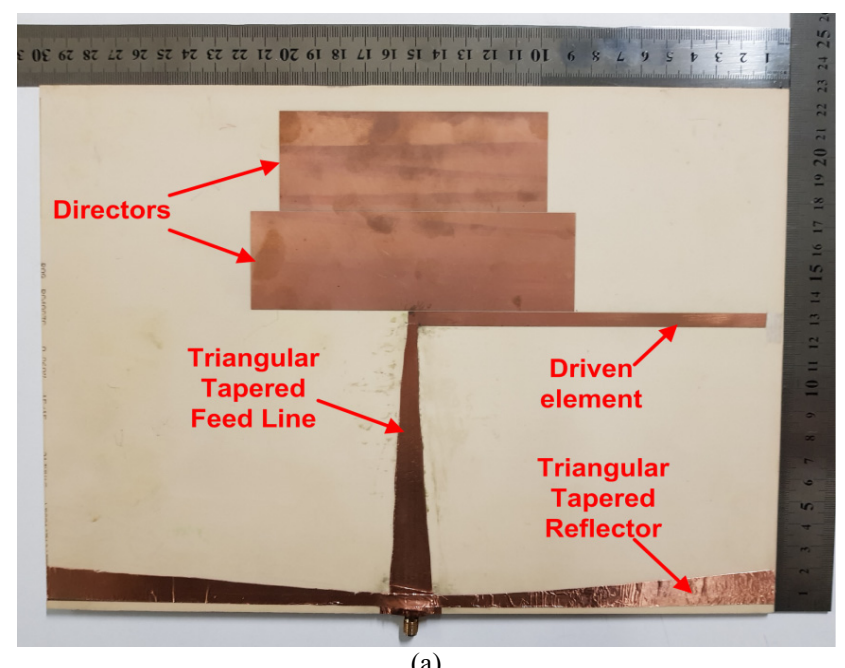

(a)

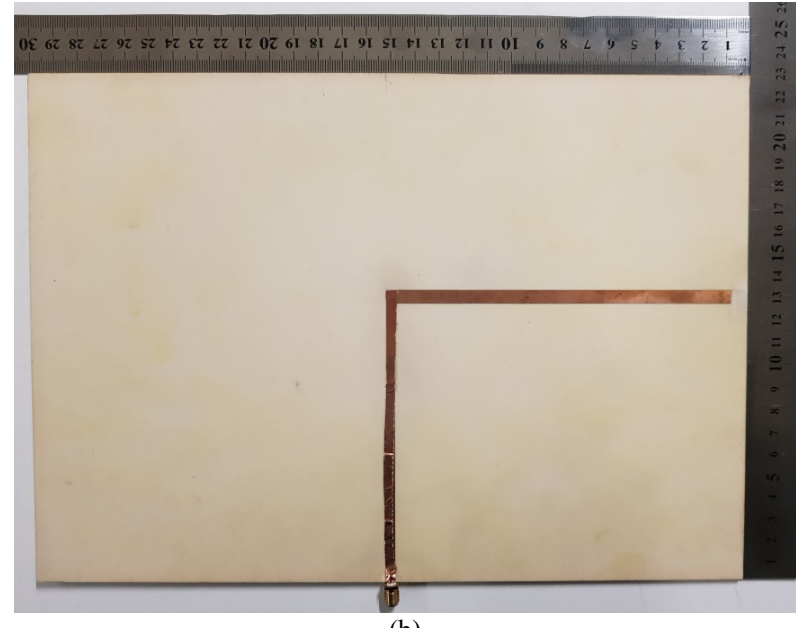

(b)

Fig. 7. The manufactured compact, planar quasi-Yagi antenna: (a) front view, (b) back view. 
with the simulation results. For this purpose, initially, the reflection coefficient $\left(\mathrm{S}_{11}\right)$ values are measured with Anritsu MS2028C Vector Network Analyzer where the corresponding measurement values are shown in Fig. 8a along with the simulated $S_{11}$ values. From the reflection coefficients in Fig. 8a, the frequency bandwidth of the proposed antenna for $10-\mathrm{dB}$ return loss is measured sufficiently wide between $428 \mathrm{MHz}$ and $896 \mathrm{MHz}$, which equals to more than $70 \%$ frequency bandwidth where the return loss values are $11.7 \mathrm{~dB}$ and $12.6 \mathrm{~dB}$ at $433 \mathrm{MHz}$ and $868 \mathrm{MHz}$, respectively.

The measurement results are also evaluated to be in good agreement with simulated ones. Although the dip (resonance) frequency at the lower band is almost same for simulation and measurement, there is a slight deviation (about 2\%) in the resonance frequency of about $800 \mathrm{MHz}$ at the upper band, which is probably due to production error and variation in the material parameters of the substrate. As given in Sec. 2.2, the parts of the antenna providing radiation mechanism at the lower band are the main (excited) dipole and the ground reflector, which have relatively larger dimensions. Thus, even for a production error of about $0.05 \mathrm{~mm}$ in the dimensions of these parts, no significant shift in the lower resonance is expected. On the other hand, since the radiation mechanism at the upper band mainly depends on the strong coupling between the main (excited) dipole and parasitic elements, a production error of $0.05 \mathrm{~mm}$ especially for gap distances between the main dipole and parasitic elements $(0.5 \mathrm{~mm})$ can make a slight shift at the upper resonance around $800 \mathrm{MHz}$. Another minor reason for this deviation might be the difference in the values of the material parameters (relative permittivity and loss tangent) of Rogers 4003C substrate used in the simulation and manufacturing. Since coupling between the main dipole and parasitic elements is partly achieved with coupled fields directly passing through substrate and surface waves, material parameters of the substrate can also affect the upper resonance frequency slightly.

For gain and radiation pattern performances of the antenna, the measurements are carried out by using a reference antenna, Keysight N9912A Fieldfox RF Analyzer, and a radiation pattern setup (Dreamcatcher) available in Antenna and Microwave Laboratory of Yasar University. The simulated and measured gain values are given in Fig. 8b. The measured gain values are found slightly higher than simulated gains especially at frequency regions around $600 \mathrm{MHz}$ and $868 \mathrm{MHz}$ due to better return loss performances at these frequency regions. From the measured gain values, the antenna is said to have more than $4 \mathrm{dBi}$ gain over the entire band of $428 \mathrm{MHz}-896 \mathrm{MHz}$. Besides, it provides minimum $4.5 \mathrm{dBi}$ gain at the frequency bands of $428 \mathrm{MHz}-500 \mathrm{MHz}$ and $800 \mathrm{MHz}-900 \mathrm{MHz}$ where the gain values are $5.6 \mathrm{dBi}$ and $5 \mathrm{dBi}$ at $433 \mathrm{MHz}$ and $868 \mathrm{MHz}$, respectively. Regarding to gain performance of the antenna, the total radiation efficiency of the proposed antenna is found at least $90 \%$ throughout the whole band (between $433 \mathrm{MHz}$ and $900 \mathrm{MHz}$ ), which is computed

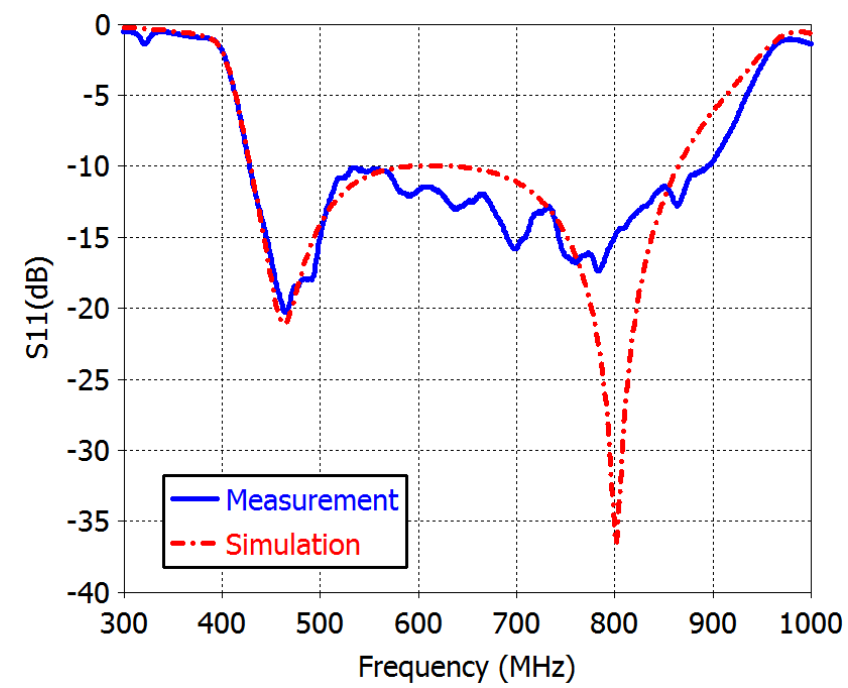

(a)

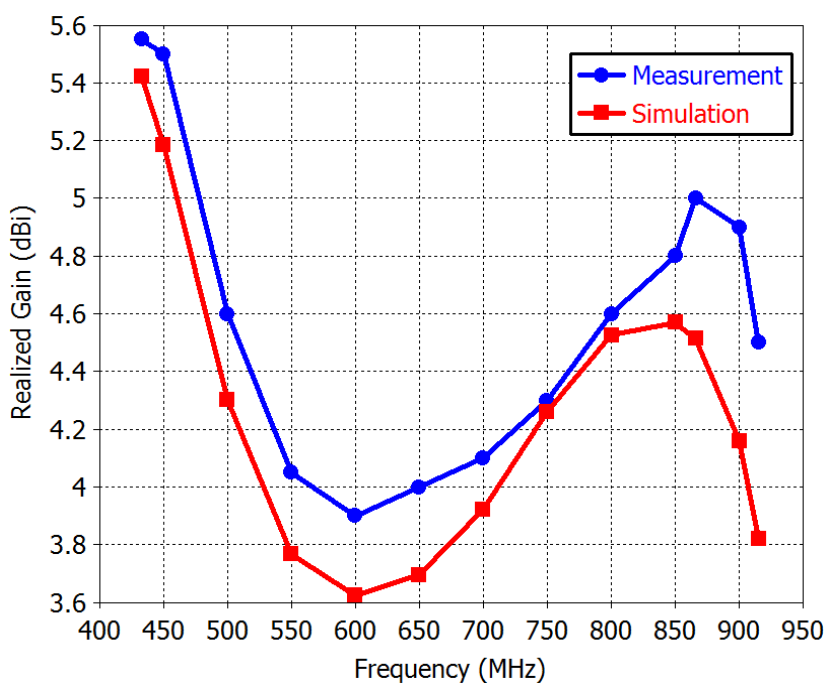

(b)

Fig. 8. (a) The simulated and measured $S_{11}$ values of the proposed antenna; (b) the simulated and measured realized peak gain values of the proposed antenna.

from dividing measured realized gain values in Fig. $8 b$ by directivity values obtained from simulations.

Finally, the radiation performance of the mentioned antenna is examined. For this purpose, the simulated and measured radiation patterns only for two focused frequencies of $433 \mathrm{MHz}$ and $868 \mathrm{MHz}$ are given in Fig. 9 for simplicity.

Here, E-plane and H-plane belong to xy plane $(\theta=$ $90^{\circ}$ plane $)$ and yz plane $\left(\phi=90^{\circ}\right.$ plane $)$ in Fig. 1 , respectively. It can be observed from these figures at which simulation and measured results are similar to each other that broadside propagation for the given frequencies is along almost $90^{\circ}$, which corresponds to $+y$ axis in Fig. 1. Therefore, the antenna can be stated to have directional characteristics, which is suitable for the applications with stationary stations.

When F/B ratio performance of the antenna is considered, these values are measured as approximately $12 \mathrm{~dB}$ 


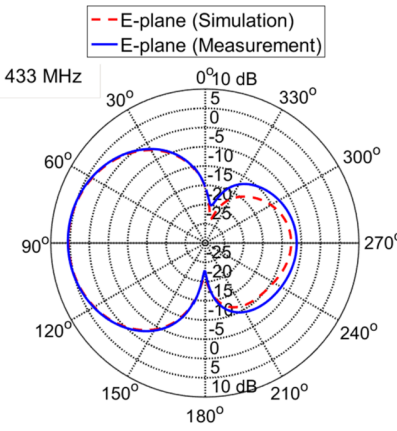

(a)

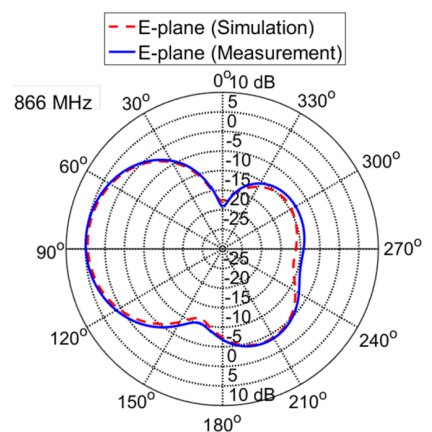

(c)

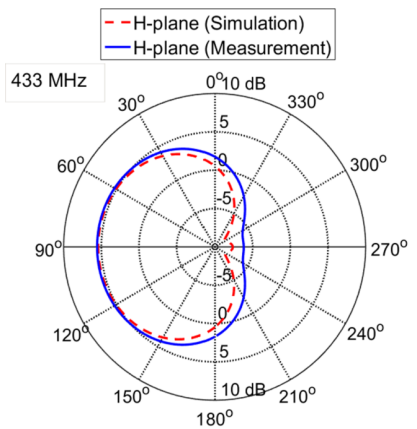

(b)

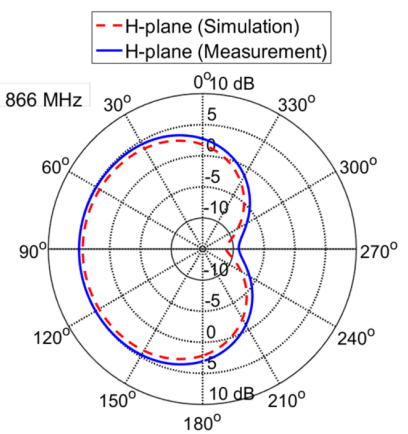

(d)
Fig. 9. The measured and simulated realized gain patterns of the antenna for (a) E-plane $\left(\theta=90^{\circ}\right.$ plane at Fig. 1) at $433 \mathrm{MHz}$; (b) H-plane ( $\phi=90^{\circ}$ plane at Fig. 1) at $433 \mathrm{MHz}$; (c) E-plane at $868 \mathrm{MHz}$, (d) for H-plane at $868 \mathrm{MHz}$.

and $14 \mathrm{~dB}$ for the stated ISM frequencies of $433 \mathrm{MHz}$ and $868 \mathrm{MHz}$, respectively. For the other frequencies within the entire band, F/B ratio values of higher than $10 \mathrm{~dB}$ are obtained at the frequency bands of $428 \mathrm{MHz}-500 \mathrm{MHz}$ and $800 \mathrm{MHz}-915 \mathrm{MHz}$. The minimum $\mathrm{F} / \mathrm{B}$ ratio value within the whole band $(428 \mathrm{MHz}-900 \mathrm{MHz})$ is found to be almost $8.5 \mathrm{~dB}$.

By considering all the measurement results described in the previous paragraphs, the designed antenna employs more than $10 \mathrm{~dB}$ return loss, $4 \mathrm{dBi}$ gain and $8.5 \mathrm{~dB} \mathrm{~F} / \mathrm{B}$ ratio values over the wideband of $428 \mathrm{MHz}-896 \mathrm{MHz}$. Moreover, it has superior performances at around two UHF ISM frequencies of $433 \mathrm{MHz}$ and $868 \mathrm{MHz}$ such that it is achieved $10 \mathrm{~dB}$ return loss, $4.5 \mathrm{dBi}$ gain and $10 \mathrm{~dB} F / \mathrm{B}$ ratio values at least for the frequency $428 \mathrm{MHz}-500 \mathrm{MHz}$ and $800 \mathrm{MHz}-900 \mathrm{MHz}$. These satisfactory performances are obtained with a compact size antenna that the overall dimensions of antenna ( $300 \mathrm{~mm}$ by $228 \mathrm{~mm}$ ) correspond to electrical size of almost $0.428 \lambda_{0} \times 0.325 \lambda_{0}$ where $\lambda_{0}$ is taken as the free-space wavelength of the lowest frequency in the band, which is equal to $428 \mathrm{MHz}$.

\section{Discussion}

As stated in Sec. 1, although there are many studies in the literature about planar Yagi antennas for different wireless communication applications, the antennas operated at UHF band (or at UHF ISM frequencies of $433 \mathrm{MHz}$ and/or $868 \mathrm{MHz}$ ) are observed to be quite narrowband. Therefore, in this section of this study, the antennas having relatively wider bandwidth and operating at different frequency bands rather than UHF are considered for the comparison. Here, the values of frequency bandwidth in percentage for $10-\mathrm{dB}$ return loss and electrical size for the lowest frequency in the band are compared for the similar antennas in the literature and the antenna in this study in order to perform the advantages of the proposed antenna in terms of wide percentage bandwidth and compact electrical size. The mentioned comparison is provided in Tab. 2 where $\lambda_{0}$ corresponds to the free-space wavelength of the lowest frequency in the frequency band of the antenna. From the results given in the comparison in Tab. 2, the antennas [15] and [19] can be classified as dual-band antennas rather than broadband antennas. Although the studies of [15], [16] and [19] can provide more compact antenna structures, the designed antenna in this study has broader frequency bandwidth as compared to frequency band of the study in [16] and any of two frequency bands considered in the studies of [15] and [19]. In Tab. 2, the antennas in [17] and [18] possess about $7.5 \%$ and $15 \%$ wider frequency band than the proposed antenna, respectively. However, the antenna in this study is more compact than these antennas in terms of total electrical size such that the antennas in [17] and [18] occupy more than $23 \%$ and $27 \%$ larger antenna size as compared to the proposed antenna, respectively.

Among all antennas in Tab. 2, the antenna in [16] has most similarity in geometry with the proposed structure. However, the lack of balun structure in [16] makes the integration of the antenna with other planar (microstrip) circuits difficult. Besides, folded main dipole and folded reflector used in [16] for the antenna miniaturization makes

\begin{tabular}{|c|c|c|c|c|}
\hline $\begin{array}{c}\text { The Antenna in } \\
\text { the Study }\end{array}$ & $\begin{array}{c}\text { Frequency Band for 10 dB } \\
\text { Return Loss [GHz] }\end{array}$ & $\begin{array}{c}\text { Bandwidth for 10 dB } \\
\text { Return Loss [\%] }\end{array}$ & $\begin{array}{c}\text { Dimensions } \\
\text { (width } \times \text { length) }[\mathrm{mm} \times \mathrm{mm}]\end{array}$ & $\begin{array}{c}\text { Electrical size } \\
\text { (width } \times \text { length) }\left[\lambda_{0} \times \lambda_{0}\right]\end{array}$ \\
\hline$[14]$ & $4.64-7.42$ & 46.1 & $50 \times 60$ & $0.773 \times 0.928$ \\
\hline$[15]$ & $0.209-0.246$ & 16.3 & $622 \times 304$ & $0.433 \times 0.212$ \\
\hline$[16]$ & $0.392-0.604$ & 42.6 & $35 \times 36$ & $0.275 \times 0.283$ \\
\hline$[17]$ & $2.36-4.74$ & 67 & $30 \times 24.24$ & $0.460 \times 0.372$ \\
\hline$[18]$ & $4.6-10.5$ & 78.1 & $50 \times 94$ & $0.307 \times 0.577$ \\
\hline$[19]$ & $1.84-4.59$ & 85.5 & $35 \times 34$ & $0.350 \times 0.340$ \\
\hline This study & $3-4.8$ & 46.1 & $300 \times 228.6$ & $0.428 \times 0.325$ \\
\hline
\end{tabular}

Tab. 2. The comparison of the performances of the antennas in this study and other similar studies. 
a gain reduction especially in the mid-band as compared to the proposed antenna, which has almost $1 \mathrm{dBi}$ better minimum peak gain within the stated frequency bands. The usage of reflector element in [16], where ground reflector is used in the proposed antenna, results in performance degradation in F/B ratio at lower band around $2.4 \mathrm{GHz}$. By considering above results, the antenna structure given in this study can be determined as the optimum design among all antennas considered in Tab. 2 in terms of the widest frequency bandwidth and the smallest antenna size.

\section{Conclusions}

In this work, a broadband planar quasi-Yagi antenna is presented. The proposed antenna has one tapered reflector and two closely spaced directors, and it is fed by a triangular tapered printed line with a feeding point patch to improve the bandwidth. The antenna has more than $70 \%$ bandwidth at $428 \mathrm{MHz}-896 \mathrm{MHz}$ that corresponds to almost entire band of UHF in addition to better performances at ISM frequencies of 433 and $868 \mathrm{MHz}$ used in LoRa, IoT, M2M, Wireless M-bus, and RFID. The antenna is relatively compact with the size of $0.428 \lambda_{0} \times 0.325 \lambda_{0}$. It has $5.5 \mathrm{dBi}$ and $5 \mathrm{dBi}$ measured realized peak gain values at 433 and $868 \mathrm{MHz}$, and gives more than $10 \mathrm{~dB} \mathrm{~F} / \mathrm{B}$ ratio where these values are minimum $4 \mathrm{dBi}$ and $8.5 \mathrm{~dB}$ over the entire frequency band. As a result, the proposed antenna can be a good candidate for wideband applications in UHF band or dual-band wireless communication applications, performed at UHF ISM bands of $433 / 868 \mathrm{MHz}$ with the enhanced performance at these frequencies.

\section{Acknowledgments}

This research was funded by Yasar University Scientific Research Project Coordination Office with Project No. BAP-0050.

\section{References}

[1] SECMEN, M. Recent Developments in Mobile Communications A Multidisciplinary Approach (Multiband and Wideband Antennas for Mobile Communication Systems). Rijeka (Croatia): Intech, 2011. ISBN: 9789533079103

[2] IVSIC, B., BONEFACIC, D., BARTOLIC, J. Reconfigurable pico-cell antenna array for indoor coverage in GSM 900 band. $R a$ dioengineering, 2009, vol. 18, no. 4, p. 388-394. ISSN: 1210-2512

[3] INTERNATIONAL TELECOMMUNICATION UNION (ITU), SWITZERLAND. Radio Regulations, edition of 2016: Volume 1: Articles. 442 pages [Online] Cited 2016-11-01 Available at: http://search.itu.int/history/HistoryDigitalCollectionDocLibrary/1. 43.48.en.101.pdf

[4] KUMBHAR, A. Overview of ISM bands and Software-Defined Radio experimentation. Wireless Personal Communications, 2017, vol. 97 , no. 3, p. 3743-3756. DOI: 10.1007/s11277-017-4696-z
[5] JÖRKE, P., BÖCKER, S, LIEDMANN, et al. Urban channel models for smart city IoT-networks based on empirical measurements of LoRa-links at 433 and $868 \mathrm{MHz}$. In IEEE 28th Annual International Symposium on Personal, Indoor, and Mobile Radio Communications (PIMRC). Montreal (Canada), 2017, p. 1-6. DOI: 10.1109/PIMRC.2017.8292708

[6] Centenaro, M., VAngelista, L., ZANELlA, A., et al. Long-range communications in unlicensed bands: The rising stars in the IoT and smart city scenarios. IEEE Wireless Communications, 2016, vol. 23, no. 5, p. 60-67. DOI: 10.1109/MWC.2016.7721743

[7] TUSET-PEIRO, P., ANGLES-VAZQUEZ, A., LOPEZ-VICARIO, J., et al. On the suitability of the $433 \mathrm{MHz}$ band for M2M lowpower wireless communications: Propagation aspects. Transactions on Emerging Telecommunications Technologies, vol. 25 , no. 12 , p. $1154-1168$, DOI: $10.1002 /$ ett.2672

[8] DIKOVIC, A., SISUL, G., MODLIC, B. A low cost platform for sensor network applications and educational purposes. Radioengineering, 2011, vol. 20, no. 4, p. 758-765. ISSN: 1210-2512

[9] JANKOWSKI-MIHULOWICZ, P., KAWALEC, D., WEGLARSKI, M. Antenna design for semi-passive UHF RFID transponder with energy harvester. Radioengineering, 2015, vol. 24 , no. 3, p. $722-728$. DOI: $10.13164 /$ re.2015.0722

[10] KUSCHEL, H. VHF/UHF radar. Part 1. Characteristics. Electronics \& Communication Engineering Journal, 2002, vol. 14, no. 2, p. 61-72. DOI: $10.1049 /$ ecej:20020203

[11] KUSCHEL, H. VHF/UHF radar. Part 2. Operational aspect and applications. Electronics \& Communication Engineering Journal, 2002, vol. 14, no. 2, p. 101-111. DOI: 10.1049/ecej:20020302

[12] BALANIS, C. A. Antenna Theory: Analysis and Design. 4th ed. New Jersey (USA): John Wiley \& Sons Inc., 2016. ISBN: 9781118642061

[13] SUN, Y. S., ZHANG, H., WEN, G., et al. Research progress in Yagi antennas. Procedia Engineering, 2012, vol. 29, p. 2116-2121. DOI: 10.1016/j.proeng.2012.01.272

[14] TA, S. X., KIM, B. C., CHOO, H. S., et al. Wideband quasi-Yagi antenna fed by microstrip-to-slotline transition. Microwave and Technology Letters, 2012, vol. 54, no. 1, p. 150-153. DOI: 10.1002/mop. 26504

[15] KIM, S., HAN, J., JANG, Y., et al. Compact VHF/UHF band quasi-Yagi antenna for multifunction radar applications. Microwave and Technology Letters, 2018, vol. 60, no. 10, p. 2525-2530. DOI: 10.1002/mop.31354

[16] DING, K., GAO, C., ZHANG, B., et al. A compact printed unidirectional broadband antenna with parasitic patch. IEEE Antennas and Wireless Letters, 2017, vol. 16, p. 2341-2344. DOI: 10.1109/LAWP.2017.2718000

[17] WANG, H., CHEN, Y., LIU, F. S., et al. Wideband and compact quasi-Yagi antenna with bowtie-shaped drivers. Electronics Letters, 2013, vol. 49, no. 20, p. 1262-1264. DOI: 10.1049/el.2013.2454

[18] WANG, H., LIU, F. S., SHI, X. W. Design of a wideband planar microstrip-fed quasi-Yagi antenna. Progress in Electromagnetics Research Letters, 2014, vol. 46, p. 19-24. DOI: 10.2528/PIERL14031702

[19] ZHANG, S., TANG, Z., YIN, Y. Wideband planar printed quasiYagi antenna with band-notched characteristic. Progress in Electromagnetics Research Letters, 2014, vol. 48, p. 137-143. DOI: 10.2528/PIERL14072507

[20] HAJIZADESH, P., HASSANI, H. R., SEDIGHY, S. H. Planar artificial transmission lines loading for miniaturization of RFID printed quasi-Yagi antenna. IEEE Antennas and Wireless Letters, 2013, vol. 12, p. 464-467. DOI: 10.1109/LAWP.2013.2253540 
[21] NIKITIN, P. V., RAO, K. V. S. Compact Yagi antenna for handheld UHF RFID reader. In Proceedings of IEEE Antennas and Propagation Society International Symposium (APS). Toronto (Canada), 2010, p. 1-4. DOI: 10.1109/APS.2010.5562224

[22] BOZDAG, G., KUSTEPELI, A. Subsectional tapered fed printed LPDA antenna with a feeding point patch. IEEE Antennas and Wireless Letters, 2015, vol. 15, p. 437-440. DOI: 10.1109/LAWP.2015.2451395

[23] OZGONUl, M. C., SECMEN, M., OKUYUCU, S. Compact printed log periodic dipole antenna with second order semi-circle iteration. In Proceedings of 25th Telecommunications Forum (TELFOR). Belgrade (Serbia), 2017, p. 1-4. DOI: 10.1109/TELFOR.2017.8249375

[24] STUtZMAN, W. L., THIELE, G. A. Antenna Theory and Design. 3rd ed. New Jersey (USA): John Wiley \& Sons Inc., 2013. ISBN: 9780470576649

\section{About the Authors ...}

Yigit BAKIRLI was born in Izmir, Turkey in 1994. He received his B.Sc. from the Department of Electrical and Electronics Engineering, Yasar University, Izmir, Turkey in 2017 and completed M.Sc. degree from the Photovoltaics
Engineering Science Hochschule Anhalt, Kothen, Germany in 2020. His research interests include remote control, printed antennas, reliability and quality of solar modules.

Ali SELEK was born in Adana, Turkey in 1994. He received his B.Sc. from the Department of Electrical and Electronics Engineering, Yasar University, Izmir, Turkey in 2017. He is currently a M.Sc. student in the Department of Electrical and Electronics Engineering, Yasar University, Izmir, Turkey. His research interests include energy monitoring, LoRa/IoT applications, smart systems and UHF antennas.

Mustafa SECMEN (corresponding author) was born in Izmir, Turkey in 1980. He received his B.Sc. and integrated Ph.D. degrees from the Department of Electrical and Electronics Engineering, Middle East Technical University, Ankara, Turkey, in 2002 and 2008, respectively. He has been a full-time Professor with the Department of Electrical and Electronics Engineering, Yasar University, Izmir since 2010. His current research interests include radar signal processing, microwave component and antenna design for satellite/mobile communications, horn and smart antennas. 